\title{
Study on the Allocating and Planning of Brands and Goods
}

\author{
Xiaoyun Wang \& Jing Wu \\ College of Art and Appareluages, Tianjin Polytechnic University \\ Tianjin 300160, China \\ E-mail: kanxinwenlianbo@163.com
}

\begin{abstract}
By the field survey, we obtained corresponding data, and established the mathematical model by the analytical hierarchy process (AHP). The mathematical model was used to analyze the rationality of the brand introduction and goods allocating and planning in the marketplace in order to enhance the competitive level of the business area, offer more shopping choices when promoting citizens' purchasing power, exert the advantage of the business area to the largest extent, generate the maximum benefit and ensure the win-win in the same types of operation.
\end{abstract}

Keywords: Business area, Brand, Goods allocation, Analytical hierarchy process (AHP)

The marketplace allocation of a mature business area should be well-proportioned, and possess different marketplace orientations, and avoid the repetition of same-class marketplace, or else, the over duplicate goods will influence of the ordered competition of the sale. How to reconstruct the new order of the business area and integrate the new skeleton of fortune has become the inevitable problem of the orienting and updating of the business area. Taking the central business street, Binjiang Street in Tianjin of China, as the example, we used four marketplaces on the same class as the research samples, and applied the mathematical model to analyze the rationality of the marketplace allocation. If the differences among marketplaces are obvious and irreplaceable, these marketplaces can be flourishing together completely, or else, the market competition will wash out the weaker one.

\section{Brand amount and type statistic in various marketplaces}

The amount statistic and occupancy rate of different types of brand in various marketplaces are respectively seen in Table 1 and Figure 1.

From the survey result, all marketplaces all emphasize the type of suit-dress, then the type of clothing and the type of sportswear.

\section{Analysis of goods in different marketplaces}

\subsection{Analysis of occupancies of different brands in various marketplaces}

The occupancies of different brands in various marketplaces are seen in Figure 2.

From the statistical data, the amount of the exclusive brands in the Quanyechang Mall is the most, and the Youyi New Land and Binjing Mall take the second place.

\subsection{Applying the mathematical model to analyze the rationality of the marketplace allocation}

AHP was first formally proposed by American operational researcher T. L. Saaty in the middle of 1970s. It is a sort of systematic and layered analysis method combining quantitative method and qualitative method. Because of its practicability and validity to process complex decision problem, it is quickly concerned in the world. AHP can not only be applied in the situation with uncertainty and subjective information, but be allowed to use experiences, insights and intuitions by the logic mode. The biggest advantage of AHP may is that it put forward the hierarchy, and it makes the observer can seriously consider and measure the importance of the index.

\subsection{Establishment of recursive hierarchy model}

According to the decision objective of "optimal rationality", we first divide the influencing factors into two sorts. The first sort is the interior factors which includes the floor layout, shopping environment, orientation, pricing and floor. The second sort if the exterior factors, i.e. the region factor. Confirm the exterior factor weight and the interior factor weight of each marketplace in all surveyed marketplaces by the principle of AHP, and compute their ratios, i.e. the "relative rationality". The hierarchy model of four marketplaces is established in Figure 3. 


\subsection{Paired comparison of the constructions of judgment matrix}

After establish the relative rationality hierarchy, we need confirming a comparison judgment matrix dominated by upper factors which are the rules of lower factors. According to the proportion nine-scale method (seen in Table 2) proposed by Professor T. L. Saaty, judge the importance of above six rationality rules, and respectively establish the comparison judgment matrixes of the rule layer to the objective layer and the project layer to the rule layer in the relative rationality hierarchy (seen in Table 3 Table 9, and the symbols in various tables correspond with the symbols in the relative rationality hierarchy model).

\subsection{Computation and consistency check of relative ordering weights of factor under single rule}

\subsubsection{Hierarchically single ordering}

The methods to solve the ordering weights of various factors include the line sum method, the square root method and the sum product method, and we adopt the square method to compute the weights.

(1) Compute the geometric average value Gi of the matrix (M) line by line.

$G_{i}=n \sqrt{\prod_{j=1}^{n} a_{i j}} \quad(\mathrm{i}$ is the line number, $\mathrm{i}=1,2 \ldots \mathrm{n})$

(2) Standardize Gi, and obtain the weight Wi.

$W_{i}=G_{i} / \sum_{i=1}^{n} G_{i}(i=1,2, \cdots, n)$

$\mathrm{W}=(\mathrm{W} 1, \mathrm{~W} 2 \ldots \mathrm{Wn}) \mathrm{T}$ is the weight vector of the computation.

(3) Compute the maximum latent root of the judgment matrix, $\lambda$ max. (Serve the consistency check).

$\lambda_{\max }=\frac{1}{n} \sum_{i=1}^{n} \frac{(M W)_{i}}{W_{i}} \quad(\mathrm{i}=1,2 \ldots \mathrm{n})$

Where, MW denotes the new vector obtained by the product of the judgment matrix $\mathrm{M}$ and the weight vector $\mathrm{W}$, and MWi is the i'th factor of MW.

\subsubsection{Consistency check}

When establishing the judgment matrix, because of the complexity of objective things and the limitation of human judgment ability, the contradiction will inevitably occur in the judgment process of importance for various factors, for example, when judging the factor $\mathrm{x} / \mathrm{y}=1: 4$ and $\mathrm{y} / \mathrm{z}=1: 2$, the situation of $\mathrm{x} / \mathrm{z}=1: 3$ may occur. So we need implementing the consistency check for the judgment matrix to test the rationality of the judgment matrix and the weight vector from the matrix. We generally use the consistency ratio index, CR, to test the rationality, and the formula is $\mathrm{CR}=\mathrm{CI} / \mathrm{RI}$.

In the formula, $\mathrm{CI}=(\lambda \max -\mathrm{n}) /(\mathrm{n}-1)$ is the consistency index, $\mathrm{RI}$ is the average random consistency index, and both of them are confirmed by large numbers of tests. Part values of the random consistency index RI are seen in Table 10. When $\mathrm{CR}<0.1$, the inconsistency degree of the matrix can be accepted, or else, we need reconstruct the judgment matrix or make necessary adjustment.

Through calculation, we can obtain the weight vectors and consistency test results of above six judgment matrixes (WB denotes the weight vector of the rule layer to the objective layer, and $W_{j}{ }^{C}$ denotes the weight vector of the project layer to the $\mathrm{j}$ 'th rule).

(1) Comparison among various rules. W_rationality $=(0.6250,1.8750,1.2500,3.7500,4.3751,3.1251) \mathrm{T}, \lambda \max$ $=6.0000552, \mathrm{CI}=0.000011, \mathrm{CR}=0.0000089<0.1$. In five exterior influencing factors, the brand repetition rate is the most important factor, then the orientation and the brand amount.

(2) Comparison among various projects.

a. Region. W_region $=(5.1189,1.7063,1.7063,3.4127), \lambda \max =3.9999625, \mathrm{CI}=0.0000125, \mathrm{CR}=0.000013<0.1$.

b. Shopping environment. W_shopping environment $=(1.2,1.6,0.4,0.8), \lambda \max =3.9999813, \mathrm{CI}=0.0000062, \mathrm{CR}$ $=0.0000065<0.1$.

c. Floor layout: $\mathrm{W} \_$floor layout $=(1.2,0.4,0.8,1.6), \lambda \max =3.999925, \mathrm{CI}=0.000025, \mathrm{CR}=0.000026<0.1$.

d. Orientation: $\mathrm{W} \_$orientation $=(1.2,1.6,0.4,0.8), \lambda \max =3.9999813, \mathrm{CI}=0.0000063, \mathrm{CR}=0.00000065<0.1$.

e. Brand repetition. W_brand repetition $=(3.9,5.2,2.6,1.3), \lambda \max =3.9999812, \mathrm{CI}=0.0000063, \mathrm{CR}=0.0000065<0.1$.

f. Brand amount. W_brand amount $=(1.6,1.3,1.2,0.8), \lambda \max =3.9997, \mathrm{CI}=0.0001, \mathrm{CR}=0.0001042<0.1$. 
From the computation results of $\mathrm{CR}$, the consistencies of six matrix is very good, and they all pass the consistency check, so we can think these six judgment matrixes and weight vectors are all reasonable.

\section{Computations of exterior factor weight and interior factor weight}

The integrated weights of various projects in the project layer to the rationality objective layer are computed by the weights of two layers (the project layer to the rule layer, and the rule layer to the objective layer) with the weighting method, and the exterior factor weight formula of each project is

$$
X_{i}=\sum_{j=1}^{5} W_{j i}{ }^{C} W_{j}^{B} \quad \text { (i is the project No., } \mathrm{i}=1,2,3 \text { ) }
$$

Where, Xi denotes the exterior factor weight of the i'th project, $W_{j i}{ }^{C}$ denotes the weight of the i'th project to the j'th rule, and $W_{j}^{B}$ denotes the weight of the $\mathrm{j}$ 'th rule to the relative rationality objective. And the matrix is $\mathrm{Z}=(33.5124$, $37.3796,19.4418,16.8206)$.

So the marketplace with the highest rationality is Youyi New Land.

\section{Conclusions}

From the result of this article, the allocating and planning of Youyi New Land is reasonable comparatively, and in the marketplace, the occupancy rate of the exclusive brand is the highest one, and according to the investigators' observation, even for the brands common with other marketplaces, its allocation of goods is largely different. In the final analysis, Youyi Mall could correctly orientate the marketplace, process the relation between the brand orientation and goods allocation, exhibit them perfectly in front of consumers, intensively attract consumers' attentions and achieve the sales intention. In the survey, some problems about the shopping centre such as the insufficient pertinence of marketplace orientation and differences of goods allocation all should be improved further. In various business forms, the special business circle possesses the strongest life-force. For any business area, with its characteristic, it will come down and aging quickly and no more people will focus on its development. To further develop itself, Chinese business area must have its characteristics.

\section{References}

Li, Jun. (2006). The Merchandising of Underwear for People in Shanghai. Journal of Xi'an University of Engineering Science and Technology, No. 1.

Zhu, Xiuli. (2007). The Study of Garment Product Development Layout. Journal of Zhejiang Sci-Tech University, No. 5 .

Table 1. Amount statistics of the brands with different types in various marketplaces

\begin{tabular}{|c|c|c|c|c|c|c|}
\hline Mall Type & Clothing & Suit-dress & Men's wear & Sportswear & Children's wear & Home textile \\
\hline $\begin{array}{c}\text { Quanyechang } \\
\text { Mall }\end{array}$ & $24 \%$ & $42 \%$ & $14 \%$ & $10 \%$ & $6 \%$ & $4 \%$ \\
\hline Hualian Mart & $24 \%$ & $32 \%$ & $15 \%$ & $20 \%$ & $6 \%$ & $3 \%$ \\
\hline $\begin{array}{c}\text { Youyi Newland } \\
\text { Mart }\end{array}$ & $32 \%$ & $17 \%$ & $19 \%$ & $22 \%$ & $7 \%$ & $3 \%$ \\
\hline $\begin{array}{c}\text { Binjiang } \\
\text { Mansion }\end{array}$ & $23 \%$ & $41 \%$ & $13 \%$ & $14 \%$ & $5 \%$ & $4 \%$ \\
\hline
\end{tabular}

Table 2. Satty proportion nine-scale system

\begin{tabular}{|c|l|}
\hline Scale & \multicolumn{1}{c|}{ Meaning of comparison } \\
\hline 1 & The i'th factor is same important with the $\mathrm{j}$ 'th factor \\
3 & The i'th factor is little more important than the $\mathrm{j}$ 'th factor \\
7 & The i'th factor is obviously more important than the $\mathrm{j}$ 'th factor \\
9 & The i'th factor is much more important than the $\mathrm{j}$ 'th factor \\
The i'th factor is extremely more important than the $\mathrm{j}$ 'th factor \\
\hline $\begin{array}{c}\text { Reciprocals of above } \\
\text { numbers }\end{array}$ & $\begin{array}{l}\text { The importance of comparison between } \mathrm{i} \text { and } \mathrm{j} \text { between paired scales } \\
\text { comparison between } \mathrm{j} \text { and } \mathrm{I} \text { is aji=1/aij }\end{array}$ \\
\hline
\end{tabular}


Table 3. A-B judgment matrix (for the total objective of relative rationality, compare the relative importance among various rules)

\begin{tabular}{|c|c|c|c|c|c|c|}
\hline $\mathrm{A}$ & B1 & B2 & B3 & B4 & B5 & B6 \\
\hline B1 & 1 & $1 / 3$ & $1 / 2$ & $1 / 6$ & $1 / 7$ & $1 / 5$ \\
\hline B2 & 3 & 1 & $3 / 2$ & $1 / 2$ & $3 / 7$ & $3 / 5$ \\
\hline B3 & 2 & $2 / 3$ & 1 & $1 / 3$ & $2 / 7$ & $2 / 5$ \\
\hline B4 & 6 & 2 & 3 & 1 & $6 / 7$ & $6 / 5$ \\
\hline B5 & 7 & $7 / 3$ & $7 / 2$ & $7 / 6$ & 1 & $7 / 5$ \\
\hline B6 & 5 & $5 / 3$ & $5 / 2$ & $5 / 6$ & $5 / 7$ & 1 \\
\hline
\end{tabular}

Table 4. B1-C judgment matrix (for the rule of region, compare the rationality among various projects)

\begin{tabular}{|c|c|c|c|c|}
\hline B1 & C1 & C2 & C3 & 3 \\
\hline C1 & 1 & 3 & 1 & $1 / 2$ \\
\hline C2 & $1 / 3$ & 1 & 1 & $1 / 2$ \\
\hline C3 & $1 / 3$ & 1 & 2 & 1 \\
\hline C4 & $2 / 3$ & 2 & 3 & \\
\hline
\end{tabular}

Table 5. B2-C judgment matrix (for the rule of shopping environment, compare the rationality among various projects)

\begin{tabular}{|c|c|c|c|c|}
\hline B2 & C1 & C2 & C3 & C4 \\
\hline C1 & 1 & $3 / 4$ & 3 & $3 / 2$ \\
\hline C2 & $4 / 3$ & 1 & 1 & 2 \\
\hline C3 & $1 / 3$ & $1 / 4$ & 2 & $1 / 2$ \\
\hline C4 & $2 / 3$ & $1 / 2$ & 1 \\
\hline
\end{tabular}

Table 6. B3-C judgment matrix (for the rule of floor layout, compare the rationality among various projects)

\begin{tabular}{|c|c|c|c|c|}
\hline B3 & C1 & C2 & C3 & C4 \\
\hline C1 & 1 & 3 & $3 / 2$ & $1 / 4$ \\
\hline C2 & $1 / 3$ & 1 & 1 & $1 / 4$ \\
\hline C3 & $2 / 3$ & 2 & 2 & 1 \\
\hline C4 & $4 / 3$ & 4 & 2 \\
\hline
\end{tabular}

Table 7. B4-C judgment matrix (for the rule of orientation, compare the rationality among various projects)

\begin{tabular}{|c|c|c|c|c|}
\hline B4 & C1 & C2 & C3 & 3 \\
\hline C1 & 1 & $3 / 4$ & 4 & 2 \\
\hline C2 & $4 / 3$ & 1 & 1 & $1 / 2$ \\
\hline C3 & $1 / 3$ & $1 / 4$ & 2 & 1 \\
\hline C4 & $2 / 3$ & $1 / 2$ & $3 / 2$ \\
\hline
\end{tabular}

Table 8. B5-C judgment matrix (for the rule of brand repetition rate, compare the rationality among various projects)

\begin{tabular}{|c|c|c|c|c|}
\hline B5 & C1 & C2 & C3 & C4 \\
\hline C1 & 1 & $3 / 4$ & $3 / 2$ & 3 \\
\hline C2 & $4 / 3$ & 1 & 1 & 4 \\
\hline C3 & $2 / 3$ & $1 / 2$ & $1 / 2$ & 1 \\
\hline C4 & $1 / 3$ & $1 / 4$ & 2 \\
\hline
\end{tabular}


Table 9. B6-C judgment matrix (for the rule of brand amount, compare the rationality among various projects)

\begin{tabular}{|c|c|c|c|c|}
\hline B6 & C1 & C2 & C3 & C4 \\
\hline C1 & 1 & 4 & $4 / 3$ & $1 / 3$ \\
\hline C2 & $1 / 4$ & 1 & 1 & $3 / 2$ \\
\hline C3 & $3 / 4$ & 3 & $2 / 3$ & 1 \\
\hline
\end{tabular}

Table 10. Values of the average random consistency index RI

\begin{tabular}{|c|c|c|c|c|c|c|c|c|c|}
\hline $\begin{array}{c}\text { Order of the } \\
\text { matrix }\end{array}$ & 1 & 2 & 3 & 4 & 5 & 6 & 7 & 8 & 9 \\
\hline RI & 0.00 & 0.00 & 0.58 & 0.90 & 1.12 & 1.24 & 1.32 & 1.41 & 1.45 \\
\hline
\end{tabular}

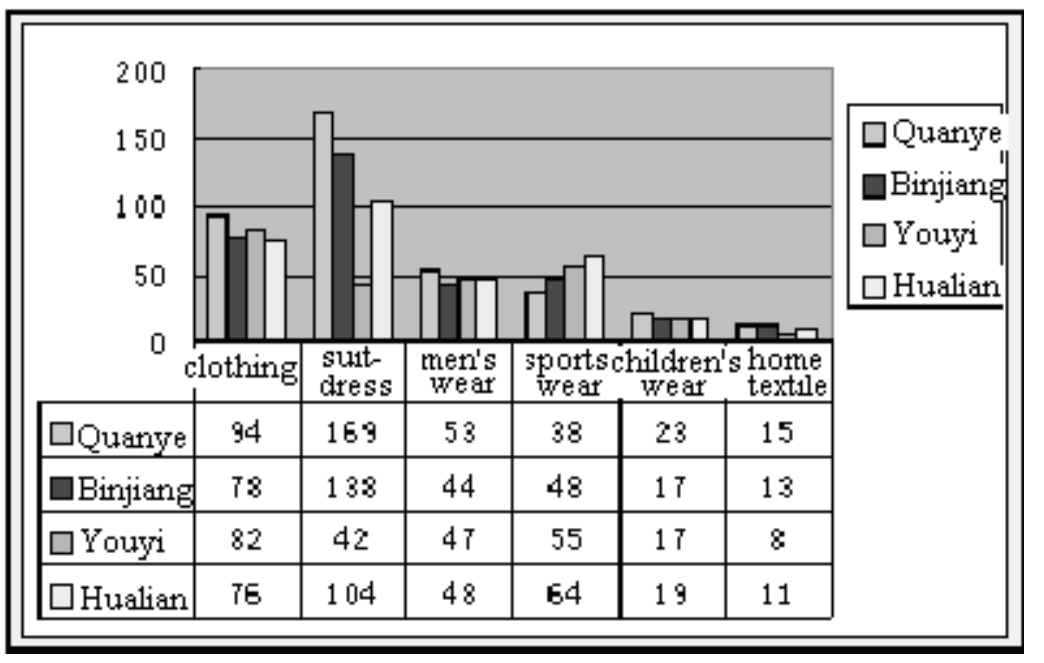

Figure 1. Occupancy Comparison of Same Type Goods in Various Marketplaces 


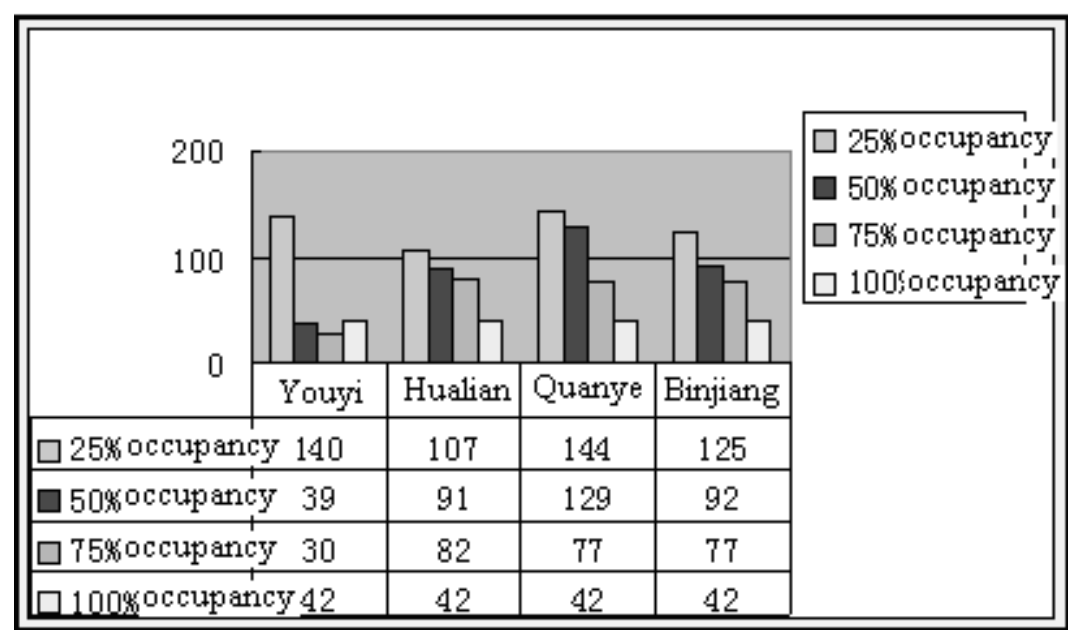

Figure 2. Occupancy Statistics of the Brands with Different Occupancies in Various Marketplaces

Note: $25 \%$ occupancy means the brand possessed by only one marketplace in four surveyed marketplaces; $50 \%$ occupancy means the brand possessed by two marketplaces together in four surveyed marketplaces; $75 \%$ occupancy means the brand possessed by three marketplaces together in four surveyed marketplaces; $100 \%$ occupancy means the brand possessed by four marketplaces together in four surveyed marketplaces.

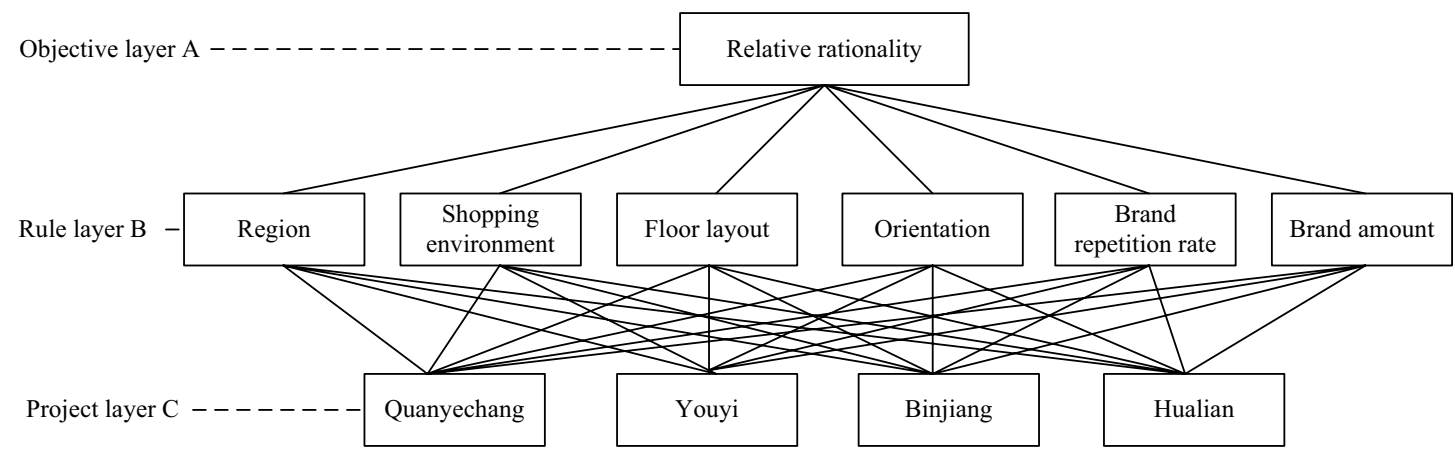

Figure 3. The Hierarchical Structure Model of Four Marketplaces 